\title{
General Physical Examination for a Cardiovascular Patient
}

\author{
Jyotsna Maddury ${ }^{1}$ Shagun Aggarwal² \\ ${ }^{1}$ Department of Cardiology, Nizam's Institute of Medical Sciences \\ (NIMS), Punjagutta, Hyderabad, Telangana, India \\ 2Department of Medical Genetics, Nizam's Institute of Medical \\ Sciences (NIMS), Punjagutta, Hyderabad, Telangana, India
}

Ind J Car Dis Wom 2019;4:42-49

The "innocent eye, which should see the world afresh, does not see it at all."

The general physical examination is important in patients with cardiovascular disease for specific diagnosis, to assess the severity and progression of the disease and, in some cases, even to know the therapeutic response.

\section{General Appearance}

Examination of the patient starts by observing the patient when he/she enters the room. We have to pay attention to the patient's functional age, posture, and general condition. If the patient is suffering from acute pain, the severity of the pain is perceived by seeing the face, the presence of diaphoresis, and posture he/she adapts. To get relief from the pericardial pain, the patient sits and leans forward and takes shallow respirations ("the praying Muslim position").

Noisy respiration with a pursed lip in sitting position supports him/her with his/her hands (fixation of the shoulder girdle facilitating the use of accessory respiratory muscles), which suggests pulmonary pathology as the cause for dyspnea. In acute beriberi and thyrotoxicosis-related dyspnea, skin is warm. Palpitation along with chest pain and sweating of palm and feet, suggestive of anxiety, may be seen in neurocirculatory asthenia (DaCosta's syndrome). If cold feet with intermittent claudication are present, we have to suspect peripheral arterial disease. Generalized cold extremities of recent onset are the manifestation of low cardiac output. Warm extremities in the presence of low cardiac output are due to palmar erythema suggests cardiac cirrhosis. Dyspnea in pale conjunctiva is due to anemia.

Icterus in a patient with cardiovascular disease (CVD) suggests liver abnormality secondary to congestive heart failure or primary liver pathologies associated with CVDs, such as viral hepatitis with myocarditis, or prosthetic valve dysfunction (hemolysis), or from hemolysis following a large pulmonary infarct or alcoholic liver disease with dilated cardiomyopathy or chronic liver disorders associated with pulmonary arteriovenous fistulas and pulmonary arterial hypertension. Emaciation suggests chronic heart failure or another systemic disorder (e.g., malignancy, infection).
Address for correspondence Jyotsna Maddury, MD, DM, FACC, FESC, FICC, Department of Cardiology, Nizam's Institute of Medical Sciences (NIMS), Punjagutta, Hyderabad 500 082, Telangana, India (e-mail: Mail2jyotsna@rediffmail.com).

\section{Skin}

1. Cyanosis and clubbing: Cyanosis and clubbing were described in detail in earlier issues of this journal.

2. Telangiectasia and hemangiomas: Cyanosis due to the right-to-left shunt through the pulmonary arteriovenous fistulas along with telangiectasia on the lips, tongue, and mucous is seen in Osler-Rendu-Weber syndrome. Tight, shiny skin with telangiectasias is due to scleroderma. Endothelial cell malignancy is called hemangiomas, which are different from the vascular malformations ( - Fig. 1). Cardiac lesions in scleroderma are pulmonary arterial hypertension, myocardial, pericardial, and endocardial diseases. ${ }^{2}$ Even long exposure to radiation such as in chronic total occlusion (CTO) interventions can produce telangiectasia on the back.

3. Skin color change: Hemochromatosis causes tanned or bronze discoloration of the skin in unexposed areas. Associated cardiac lesions are restrictive or dilated cardiomyopathy. ${ }^{3}$

4. Petechiae and ecchymosis: The drugs that can produce petechiae are anticoagulation or antiplatelet drugs. Leukocytoclastic vasculitis or infective endocarditis can also produce petechiae due to thrombocytopenia.

5. Xanthomas: Subcutaneous accumulation of the fat is called xanthomas. Presence of xanthomas represents the lipid disorder. Usually, they are present along the tendon sheaths or on the extremities over the extensor surfaces. If they are present on eyelids, they are called xanthelasma. There are varieties of xanthomas:

a. Striated xanthomas are yellowish streaks seen in the palm, which are specific for type III hyperlipoproteinemia.

b. Tuberous xanthomas are yellowish, coalescing nodules seen on the elbows or knees.

c. Eruptive xanthomas are seen on the arms, legs, and buttocks. These are erythematous halos with central yellow-orange papules.

6. Pseudoxanthoma elasticum: Axillary skin shows the leathery, tannish yellowish papules giving cobblestone (plucked chicken) appearance in 


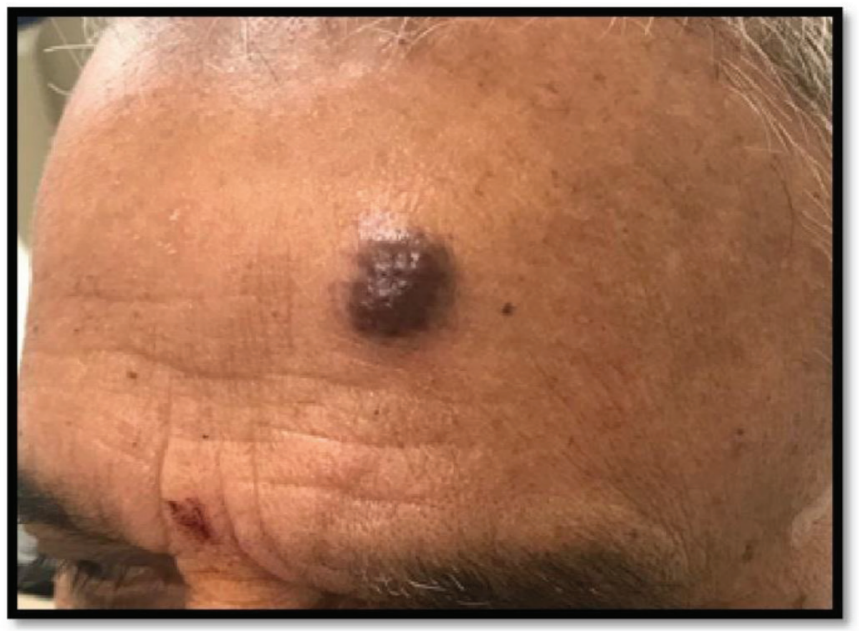

Fig. 1 Hemangioma-this patient had pulmonary arteriovenous malformation also.

pseudoxanthoma elasticum. The associated cardiovascular disorders are accelerated atherosclerosis and endocardial lesions. ${ }^{4}$

7. Lentigines: Lentigines are freckle-like brown macules and café-au-lait spots over the trunk and neck ( - Fig. 2). These are seen in Leopard, Lamb, and Carney's syndromes, and also with the multiple atrial myxomas, atrialseptal defect (ASD), hypertrophic cardiomyopathy (HCM), and valvular stenoses.

8. Cutaneous sarcoid: Lupus pernio, erythema nodosum, granuloma annulare, or yellowish-brown papules, nodules, or plaques indicate cutaneous sarcoid. Usually, these lesions are associated with pruritus. Cardiac sarcoidosis manifests as pericardial effusion, pulmonary hypertension, complete heart block, ventricular arrhythmias, congestive heart failure, and ventricular aneurysms.

9. Erythromelalgia: Periodically skin becomes hot and red, due to arteriolar dilation. This condition is associated with hypertension and venous insufficiency.
10. Livedo reticularis: The marbling reticulation or fishnet type of mottling is called the livedo reticularis. It is seen in the lower trunk, buttocks, and extremities. Precipitating factors are emotion and exposure to clod. Its presence represents the underlying connective tissue disorders such as lupus erythematosus, periarteritis nodosa, or cryoglobulinemia. Livedo reticularis in a man of 50 years suggests cholesterol embolization from an abdominal aortic aneurysm.

11. Carcinoid faces: Intermittent episodes of red and purple color changes of the skin on the face suggest underlying carcinoid disease. In a long-standing case, even telangiectasias are seen.

12. Pheochromocytoma: Crowe's sign means axillary freckling that is a feature in pheochromocytoma along with neurofibromatosis and cafe-au-lait spots.

13. Acromegaly: Large stature, coarse facial features, "spade" hands. Associated with cardiac hypertrophy.

14. Pickwickian syndrome: This syndrome is seen in markedly obese person. They present with somnolence
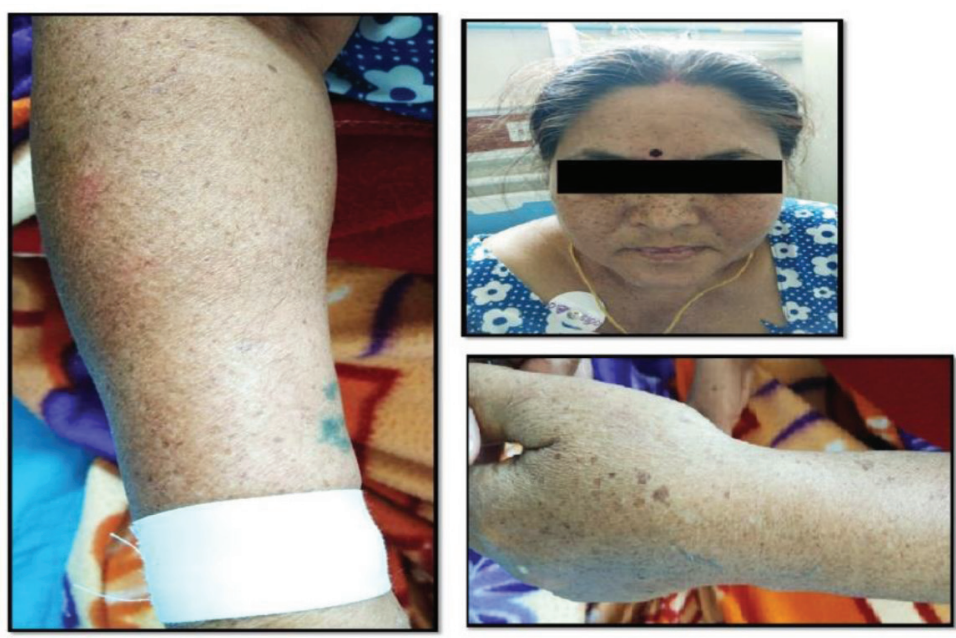

Fig. 2 Lentiginosis-this patient has hypertrophic cardiomyopathy (HCM) in addition. 
and dyspnea. Associated with pulmonary hypertension. To classify the obesity, usually body mass index (BMI) is taken, but cardiac risk due to abnormal body fat distribution is detected by waist circumference (WC) and waist-to-hip ratio (WHR). ${ }^{5}$

15. Facies of supravalvular aortic stenosis: A flattened occiput, broad high forehead, puffy cheeks, ocular hypertelorism with strabismus, low ears, a large mouth, patulous lips, small chin, underdeveloped nasal bones, upturned nose with a long filtrum (the vertical groove between the nose and mouth), dental abnormalities, and hypoplastic mandible are seen in William's syndrome. Cardiac lesions expected in this syndrome are supravalvular aortic stenosis (AS), ASD, and ventricular septal defect (VSD) (- Table 1).

16. Facies of down syndrome: In this condition, the facial features include a flattened occiput, disproportionately small head, inner epicanthal folds that give the impression of slanted eyes, Brushfield's spots (a circle of punctate, de-pigmented dots circumferentially arranged at the periphery of the iris), congenital coloboma or fissures of the iris (looks like cats eye), and a mouth held open by a large protruding tongue. In extremities, the fourth and fifth fingers are abnormally separated, and the fifth finger is short. A distal triaxial radius, curved inward Simian crease traversing the palm, and hypotonia of the limbs during infancy are present. Hypotonia improves as the child grows. ${ }^{6}$ Cardiac lesions associated with this syndrome vary from simple ASD, VSD to complex endocardial cushion defects.

17. Facies of myxedema: A patient with hypothyroid has puffy lids, loss of hair in the outer third of the eyebrows, scanty and dry hair, coarse and dry skin, expressionless face, and an enlarged tongue. Associated with cardiomyopathy and pericardial effusion ( - Table $\mathbf{1}$ ).

18. Friedreich's ataxia and other neuromuscular disorders: Lurching gait, hammertoe, Pes cavus with hammer toe, and nystagmus suggest Friedrich's ataxia, which is associated with HCM. In Duchenne's dystrophy (slow, clumsy waddling gait caricatured by exaggerated lumbar lordosis and protuberant abdomen), the posterobasal left ventricular wall involvement is specific. Myotonic muscular dystrophy patient looks aged with graying of hair and boldness with expressionless face and cataracts. Usually, the convexity of scoliosis is to the right; if it occurs to left, we have to suspect systemic neuromuscular disease or poliomyelitis. Abnormal cardiac impulse formation and conduction are seen in these varieties of neuromuscular disorders.

19. Facies of Werner's syndrome: Premature aging is the characteristic feature of this syndrome. Face reflects all

Table 1 Facial features and other systemic findings in patients with important genetic cardiac diseases

\begin{tabular}{|c|c|c|c|}
\hline Syndrome & Facial dysmorphism & Other characteristic features & Type of cardiac defect \\
\hline $\begin{array}{l}\text { Williams' } \\
\text { syndrome }\end{array}$ & $\begin{array}{l}\text { Periorbital fullness, epicanthal folds, bitemporal } \\
\text { narrowing, broad forehead, short nose, broad } \\
\text { tip, malar flattening, long philtrum, thick lips, } \\
\text { large mouth, large ear lobes }\end{array}$ & $\begin{array}{l}\text { Overfriendliness, attention deficit, } \\
\text { intellectual disability, soft and lax } \\
\text { skin, hernia }\end{array}$ & $\begin{array}{l}\text { Supravalvular aortic } \\
\text { stenosis (75\%), peripheral } \\
\text { pulmonary stenosis }\end{array}$ \\
\hline $\begin{array}{l}22 \mathrm{q} 11.2 \\
\text { deletion } \\
\text { syndrome }\end{array}$ & $\begin{array}{l}\text { Hooded eyelids, hypertelorism, orofacial cleft, } \\
\text { asymmetric crying facies, ear abnormalities, a } \\
\text { square tip of the nose, small mouth }\end{array}$ & $\begin{array}{l}\text { Hypocalcemia, immunodeficiency, } \\
\text { velopharyngeal insufficiency, learn- } \\
\text { ing disability, psychiatric symptoms }\end{array}$ & Conotruncal defects \\
\hline $\begin{array}{l}\text { Turner's } \\
\text { syndrome }\end{array}$ & $\begin{array}{l}\text { Hypertelorism, epicanthal folds, neck } \\
\text { webbing, low hairline, small mandible, } \\
\text { increased pigmented nevi }\end{array}$ & $\begin{array}{l}\text { Short stature, ovarian failure, shield- } \\
\text { like chest, cubitus valgus, short } \\
\text { fourth metacarpals, renal anomalies }\end{array}$ & $\begin{array}{l}\text { Coarctation of aorta, } \\
\text { bicuspid aortic valve }\end{array}$ \\
\hline $\begin{array}{l}\text { Noonan's } \\
\text { syndrome }\end{array}$ & $\begin{array}{l}\text { Hypertelorism, ptosis, downslanting } \\
\text { palpebral fissures, low set posteriorly } \\
\text { rotated ears with fleshy helices }\end{array}$ & $\begin{array}{l}\text { Short stature, neck webbing, } \\
\text { pectus deformity, cryptorchidism, } \\
\text { learning disability }\end{array}$ & $\begin{array}{l}\text { Pulmonary valve stenosis, } \\
\text { hypertrophic cardiomyop- } \\
\text { athy, ECG abnormalities }\end{array}$ \\
\hline $\begin{array}{l}\text { Down's } \\
\text { syndrome }\end{array}$ & $\begin{array}{l}\text { Brachycephaly, flat facies, upslanting } \\
\text { palpebral fissures, epicanthal folds, open } \\
\text { mouth with tongue protrusion, low-set ears }\end{array}$ & $\begin{array}{l}\text { Intellectual disability, low hairline, } \\
\text { hypotonia, brachydactyly, simian } \\
\text { crease, sandal gap, duodenal } \\
\text { atresia, tracheoesophageal fistula, } \\
\text { hearing deficits, atlantoaxial dislo- } \\
\text { cation, increased risk of leukemia }\end{array}$ & $\begin{array}{l}\text { Septal defects-AVSD, } \\
\text { VSD, ASD }\end{array}$ \\
\hline Trisomy 18 & $\begin{array}{l}\text { Prominent occiput, retrognathia, low-set } \\
\text { dysplastic ears, small eyes, mouth, and nose }\end{array}$ & $\begin{array}{l}\text { Multiple internal malformations, } \\
\text { overlapping fingers, rocker bottom } \\
\text { feet or heel prominence, arthrogry- } \\
\text { posis, limb defects, early lethality }\end{array}$ & $\begin{array}{l}\text { Septal defects, complex } \\
\text { cardiac defects }\end{array}$ \\
\hline Trisomy 13 & $\begin{array}{l}\text { Midline cleft lip, hypotelorism, } \\
\text { micro-ophthalmia, dysplastic ears }\end{array}$ & $\begin{array}{l}\text { Holoprosencephaly, renal anomalies, } \\
\text { postaxial polydactyly, multiple } \\
\text { internal malformations, early lethality }\end{array}$ & $\begin{array}{l}\text { Septal defects, complex } \\
\text { cardiac defects }\end{array}$ \\
\hline $\begin{array}{l}\text { Marfan's } \\
\text { syndrome }\end{array}$ & $\begin{array}{l}\text { Long, narrow face, malar hypoplasia, } \\
\text { retrognathia, deep-set eyes with a } \\
\text { downward slant, high-arched palate }\end{array}$ & $\begin{array}{l}\text { Ectopia lentis, tall stature, arach- } \\
\text { nodactyly, dolichostenomelia joint } \\
\text { laxity, pectus deformity, Scoliosis }\end{array}$ & $\begin{array}{l}\text { Aortic root dilatation, } \\
\text { predisposition to } \\
\text { aneurysm formation and } \\
\text { rupture, valvular prolapse }\end{array}$ \\
\hline
\end{tabular}

Abbreviations: ASD, atrial septal defect; AVSD, atrioventricular septal defect; ECG, electrocardiogram; VSD, ventricular septal defect. 
features of aging such as graying of hair, cataract, boldness, etc. Atrophic, tightly drawn skin, ischemic ulcers, and hypoplastic nails due to peripheral vascular disease associated with this syndrome, in addition to premature coronary and systemic atherosclerosis. ${ }^{7}$

20. Hound-dog face: Hound-dog facies typically described in cutis laxa (dermatochalasis). The face looks prematurely aged with an antimongoloid slant, slightly everted nostrils, prominent ears, and epicanthic folds and associated with premature atherosclerosis. In contrast to Ehlers-Danlos syndrome, there is no joint laxity. ${ }^{8}$

21. Potter's face: In Potter's syndrome, there is hypertelorism, prominent epicanthal folds, low-set ears, receding chin, and flattened nose. There may be ventricular septal defect, endocardial cushion defect, tetralogy of Fallot, and patent ductus arteriosus. ${ }^{8}$

22. Aortic face: Also called Corvisart's face, due to aortic regurgitation (AR) with congestive heart failure-puffy, cyanotic, with swollen eyelids, and shiny eyes. ${ }^{9}$

23. Ankylosing spondylitis: This condition causes straight back syndrome and a stiff spine. It can be associated with AR and heart block.

24. Sickle cell anemia: During a painful crisis time in sickle cell anemia, the patient may develop cutaneous ulcers. These patients can have pulmonary hypertension and secondary cardiomyopathy.

25. Rheumatoid arthritis: Typical hand deformity and the presence of subcutaneous nodules give a clue for rheumatoid arthritis (RA) diagnosis. RA patients may have the myocardial, pericardial, and endocardial disease. ${ }^{2}$

26. In Graves' disease, occasionally on the distal extremities, symmetrical vitiligo may be there.
27. The subtle, small, translucent, waxy, flat-topped nodules are seen on the skin and in the eye, which can be better appreciated with a hand lens to see these small lesions, in systemic amyloidosis. Taking a punch biopsy from these nodules yields more positive diagnosis of amyloidosis.

28. Subcutaneous nodules of acute rheumatic fever vary from very small like pinhead to as large as 1 to $2 \mathrm{~cm}$, unattached to the skin, seen commonly on the bony prominences of the elbows, dorsa of the hands or feet, and malleoli or vertebrae.

29. Yellow to orange-red nevi of different sizes called adenoma sebaceum are seen on the malar and nasolabial skin, in tuberous sclerosis and sometimes accompanied by cardiac rhabdomyoma.

30. Loeys-Dietz syndrome (LDS): Features include dolichocephaly, hypertelorism, enophthalmos, downslanting palpebral fissures, bifid uvula, retrognathia, pectus carinatum, arachnodactyly, and increased arm span. Cardiac lesions are aortopathy, vasculopathy, and mitral valve prolapse. ${ }^{10}$

\section{Specific for Infants and Children}

1. Neonatal gigantism is a feature of the infant of a diabetic mother. ${ }^{11}$

2. Noonan's syndrome (-Fig. $\mathbf{3}$ ). has a normal chromosomal pattern with phenotypic features of Turner's syndrome. Dwarfism may not be there. Cardiac lesions are dysplastic pulmonary valve stenosis or hypertrophic obstructive cardiomyopathy. ${ }^{12}$

3. The Ellis-van Creveld (EVC) syndrome is characterized by dwarfism and polydactyly. ${ }^{13}$
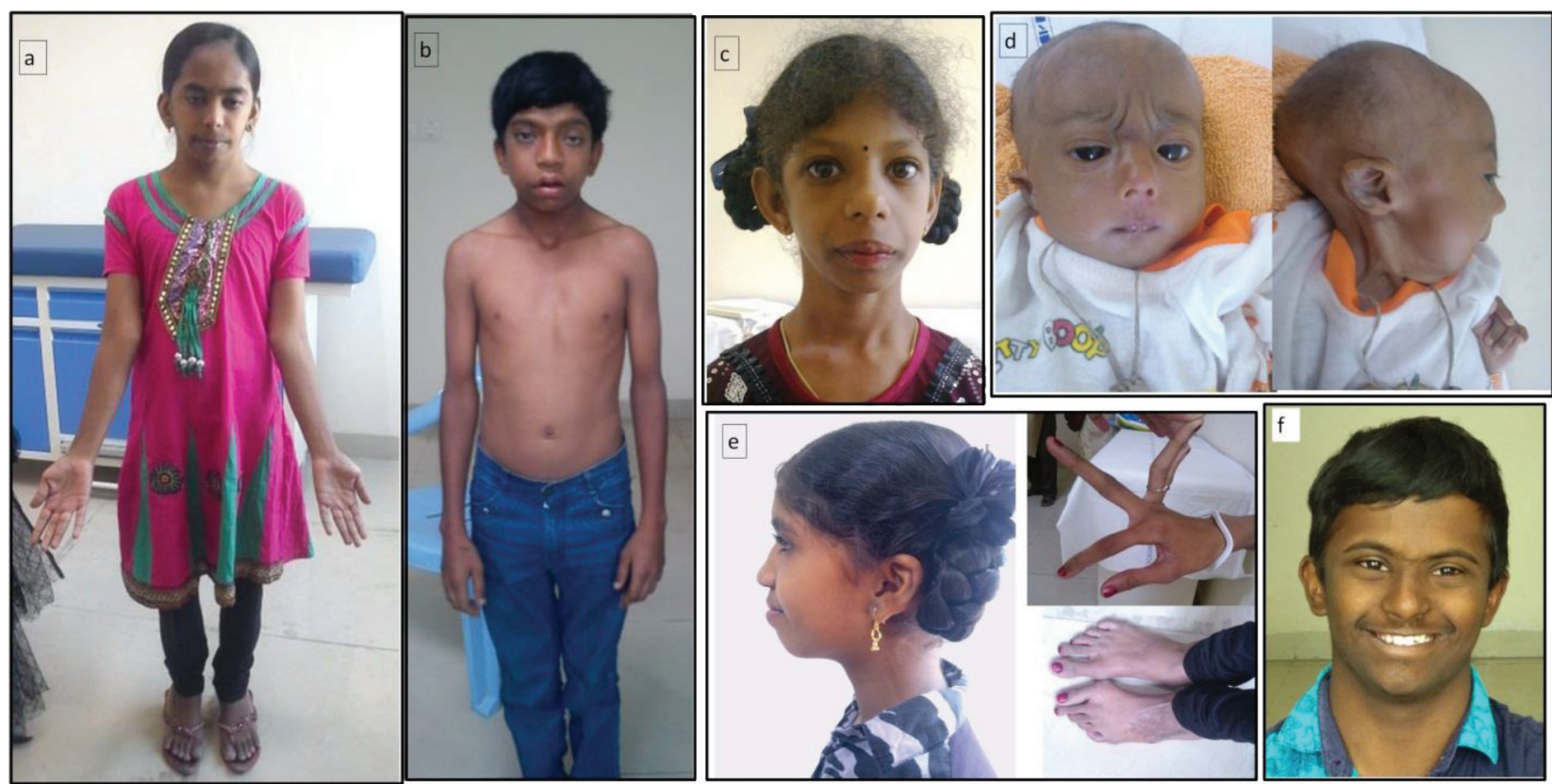

Fig. 3 Phenotypic features of few important syndromes. (a) Patient with Turner's syndrome with features such as neck webbing, cubitus valgus, and facial dysmorphism. (b) Patient with Noonan's syndrome depicting ptosis, facial dysmorphism, and pectus deformity. (c) Patient with William's syndrome depicting characteristic facies with bitemporal narrowing, periorbital fullness, long philtrum, and thick lips. (d) Patient with trisomy 18 showing facial dysmorphism, prominent occiput, and overlapping fingers. (e) Patient with Marfan's syndrome with long face, malar hypoplasia, retrognathia, arachnodactyly, and finger joint laxity. (f) Patient with Down's syndrome showing flat face, upslanting palpebral fissures, epicanthal folds, and small ears. 
4. In Hutchinson-Gilford syndrome, premature aging and atherosclerosis are features.

5. Gargoylism is a feature in Hurler's syndrome. In this malformed skull, the features include prominent supraorbital ridges, depression of nasal bridge, and thick lips with peg teeth. Cardiac associations are mitral and aortic valves involvement and narrowing of the lumina of the coronary arteries. ${ }^{13}$

6. In fetal alcohol syndrome, the baby has short palpebral fissures, a hypoplastic upper lip with thin vermilion, diminished to absent philtrum, micrognathia, and midfacial growth deficiency. ${ }^{14}$ This condition occurs when maternal ingestion of alcohol is massive during gestation. Associated cardiac anomalies are ASD or VSD alone or with pulmonary valve stenosis.

7. In the cardiofacial syndrome, the child has a unilateral partial lower facial weakness that becomes more prominent during crying. Cardiac lesions are VSD and coarctation of aorta. ${ }^{15}$

\section{Head and Neck}

1. A high-arched palate is a feature of Marfan's and other connective tissue disease syndromes.

2. A large protruding tongue with parotid suggests amyloidosis. It is associated with restrictive cardiomyopathy.

3. In LDS, the vascular lesions can be seen in the cerebral, thoracic, and abdominal arteries in the form of aneurysms and/or dissections. Multiple skeletal manifestations such as pectus excavatum or pectus carinatum, scoliosis along with craniofacial features of widely spaced eyes, and strabismus are present. Mainly, skin is velvety and translucent with easy bruising and with dystrophic scars.

4. Long-term ingestion of amiodarone causes deep blue discoloration around the malar area and nose. ${ }^{16}$

5. Orange tonsils are characteristic of Tangier's disease.

6. Ptosis and ophthalmoplegia occur in muscular dystrophies. For example, in Kearns-Sayre syndrome, ptosis is asymmetrical, and the external ophthalmoplegia with pigmentary retinopathy is seen. In this condition, infranodal conduction abnormalities are culminating in complete heart block. ${ }^{17}$

7. Proptosis is seen in Graves' disease, severe tricuspid regurgitation (TR). Lid lag and stare are addition points for the Graves' hyperthyroidism. Proptosis in patients with severe TR may be accompanied by systolic anterior movement of the ocular bulb that is best detected when the examiner observes the eyes with an oblique light while the patient sits and looks directly forward.

8. The findings in osteogenesis imperfecta are blue sclerae, mitral regurgitation (MR) and AR, and frequent spontaneous fractures.

9. Fundus examination is essential in the evaluation of patients with hypertension (four gradesgrade 1: generalized attenuation-arteriovenous ratio of $<2-3$; grade 2: focal constriction or spasm; grade 3: hemorrhages and exudates, exudates may either resemble cotton wool or be hard and shiny; grade 4: papilledema), atherosclerosis (grade 1: the light reflex is increased in width; grade 2: crossing abnormalities-arteriovenous nicking and right-angled crossing of the arteries over the veins; grade 3: copper-wire arteries-red color of the artery is slightly brownish due to thick walls; grade 4: silver-wire arteries-no red color is seen, only a whitish light reflex), diabetes, toxemia of pregnancy or in young persons with rapid onset of hypertension (pure attenuation of the arterioles), endocarditis (oval- or canoe-shaped hemorrhages near optic disk with white spot in center-Roth's spots), neurologic signs or symptoms, Hollenhorst's plaques (flakes of cholesterol emboli seen as glinting spots, often seeming larger than the vessels in which they reside, highly refractile), ${ }^{18}$ fibrin-platelet emboli (whitish plugs sometimes seen moving through the retinal arteries), coarctation of aorta (corkscrew tortuosity with frequent "U turns" without hypertensive changes), ${ }^{12}$ or known carotid or aortic arch disease. Fundus changes observed in cyanotic congenital heart disease and at high altitude include an increase in retinal vascularity and an increase in vascular caliber probably due to vascular endothelial growth factor, and, exceptionally, papilledema and retinal edema may occur.

10. Retinal detachment may occasionally be in EhlersDanlos syndrome. Also, skin exhibits remarkable hyperextensibility, with a rubber-like response to stretch and with cigarette paper scars that result from fragility and poor healing.

11. Lacrimal gland hyperplasia is sometimes a feature of sarcoidosis. Eversion of the lid permits direct inspection of the enlarged lacrimal glands. ${ }^{19}$

12. Malar flush-The "mitral facies" of rheumatic mitral stenosis (pink-purplish patches with telangiectasias over the malar eminences) also can accompany other disorders associated with pulmonary hypertension and reduced cardiac output.

13. In EVC syndrome, there may be prematurely erupted teeth present at birth along with gingival hypertrophy and multiple frenuls. ${ }^{12}$ EVC syndrome reveals a characteristic pattern of atrioventricular (AV) canal defects with systemic and pulmonary venous abnormalities and heterotaxy syndromes.

14. Retraction of the tongue-glossoptosis-in the Pierre Robin syndrome. The retraction may cause upper airway obstruction and pulmonary hypertension. ${ }^{20}$

15. Relapsing polychondritis is suggested by inflammation of the pinnae and nasal association with a saddle-nose deformity. Cardiac lesions are aortic incompetence, mitral regurgitation, complete AV block, and pericarditis.

16. De Musset's sign (Lincoln's sign)-Bobbing of the head in significant AR is due to increased carotid arterial pulsations striking the angles of the mandibles. The patient appears to be nodding "yes." 
17. Patients with significant TR will exhibit lateral head movement. This occurs when regurgitant blood in the superior vena cava (SVC) strikes the right mandibular angle. The patient appears to be nodding "no."21

18. The thyroid gland has to be palpated for its size, symmetry, and consistency.

19. Earlobe crease: Earlobe crease is an oblique crease in the earlobe. Ninety percent of patients older than 50 years with significant triple-vessel coronary disease have a deep earlobe crease.

20. Eyes

a. Corneal arcus: This condition is associated with hypercholesterolemia. It has to be differentiated from the arcus senilis that is not associated with hypercholesterolemia. Corneal arcus is a thick band starts inferiorly and inside the limbus. Thin rim of iris can be seen between the corneal arcus and sclera. On the contrary, in arcus senilis, the arcus that starts superiorly extends to the rim or limbus of the iris.

b. Cataract in children: Consider rubella syndrome, myotonic muscular dystrophy, and Werner's syndrome. ${ }^{12}$

c. Argyll Robertson pupil (reacts to accommodation but not to light)-suspect luetic aortic aneurysm or luetic AR with ostial coronary stenosis.

d. Exophthalmos: Thyrotoxicosis with heart failure, severe TR.

e. Tremulous iris (iridodonesis)-Marfan's syndrome: In Marfan's syndrome, lens subluxation is typically upward, whereas in homocystinuria, downward dislocation is the rule. Homocystinuria is accompanied by systemic arterial and venous thromboses, myocardial infarction, and pulmonary embolism.

f. Blue sclera is seen in osteogenesis imperfecta (associated with AR), Marfan's syndrome (associated with great-vessel aneurysms and mitral or aortic valve regurgitation), and Ehlers-Danlos syndrome (associated with the atrial septal defect, tetralogy of Fallot, or regurgitant valves).

g. Angioid streaks are brown linear streaks perpendicular to blood vessels seen in pseudoxanthoma elasticum, Paget's bone disease, and sickle cell anemia. Cardiac lesions are endocardial fibrosis and regurgitation of the valves.

h. Conjunctivitis with urethritis points to the diagnosis of Reiter's disease. Acute cardiac involvement takes the form of pericarditis and abnormalities in AV conduction, whereas chronic involvement is represented by AV block and AR. ${ }^{22}$

i. Staphyloma: Congenital staphyloma is a component of Kabuki's syndrome. The cardiac defects in this syndrome are coarctation of the aorta and atrial and ventricular septal defects.

\section{Extremities}

1. Clubbing implies the presence of central shunting (described in the previous issue of this journal).
2. In Holt-Oram syndrome, the unopposable "fingerized" thumb is present. The thumb may be hypoplastic with an accessory phalanx (triphalangeal). The most common coexisting cardiac anomaly is an ostium secundum ASD. ${ }^{12}$

3. Arachnodactyly is a feature of the Marfan's syndrome.

4. Signs of infective endocarditis include Janeway lesions, Osler's nodes, and splinter hemorrhages.

a. Janeway lesions are seen in palms and soles. These are nontender, circular or oval, pink to tan macules with slightly raised areas of hemorrhage. Usually small size of $5 \mathrm{~mm}$ macules, which does not blanch with pressure.

b. Osler's nodes are seen on the pads of the fingers or toes. They are tender and raised nodules, occasionally with a whitish center, of variable diameters (3-15 mm).

c. Splinter hemorrhages do not occur due to embolic phenomenon, are linear in the mid-nailbed. Embolic splinters are subungual. Fresh red hemorrhages are more important than brown linear streaks.

d. Localized linear scars along the course of antecubital veins imply "mainline" intravenous drug abuse with the risk of staphylococcic bacteremia and right-sided infective endocarditis.

5. Examine the hands for tobacco staining. ${ }^{23}$

6. "Half and half nails" (proximal portion white to pink and distal portion red or brown: Terry's nails)-chronic renal failure, cirrhosis.

7. Paired, transverse, white nail bands in the second, third, and fourth fingers (Muehrcke's lines) suggest chronic hypoalbuminemia. These types of nails are present in three-fourths of the patients with nephrotic syndrome, liver disease, and malnutrition..$^{24}$

8. In Quincke's pulse, after slight compression of the nailbed, there is alternate red blanching of the fingernails, coinciding with each cardiac cycle. Quincke's pulse is a sign of AR.

9. Capillary refill time (CRT): By nail blanching, we can assess the volume status at the bedside. Keep the hand at the heart level, and then compress and release the distal phalanx of the middle finger and observe the time taken to get the normal color of the finger. Two seconds in children and adult men, 3 seconds in adult women, and 4.5 seconds in elderly persons are normal..$^{25}$

10. Pedal edema may occur due to heart failure, venous insufficiency, or drug-induced-like dihydropyridine calcium channel blockers or other fluid-retaining drugs.

11. Chronic venous insufficiency may be represented by extensive varicosities, medial ulcers, or brownish pigmentation from hemosiderin deposition.

12. Asymmetric swelling can occur due to unilateral venous thrombosis, the sequelae of previous vein graft harvesting, or lymphatic obstruction.

13. Homan's sign is the calf pain elicited by forceful dorsiflexion of the foot. Even though its presence is a clue to deep vein thrombosis (DVT), it is neither specific nor sensitive for DVT. 
14. Chronic arterial insufficiency is represented by muscular atrophy and the absence of hair in an extremity.

15. Lipodystrophy is the redistribution of fat from the extremities to central/abdominal stores and may relate to antiretroviral treatment or be associated with insulin resistance.

16. Features of Marfan's syndrome: Fingers are slender and long ("spider" fingers or arachnodactyly), thumb sign (when a fist is made over a clenched thumb, the thumb should not extend beyond the ulnar side of the hand), wrist sign (when the thumb encircles the wrist, the little finger will overlap at least $1 \mathrm{~cm}$ ), and the span of the outstretched arms exceeds the height by at least $5 \mathrm{~cm}$. Usually sitting height is one-half of the total height or arm span. In Marfan's syndrome and hypogonadism, arm span is more than the sitting height. ${ }^{26}$

17. Jaccoud's arthritis is the sequelae of the postrheumatic fever. The deformity occurs due to the subluxation of the joints but not due to the erosion and can be corrected voluntarily. ${ }^{27}$

18. Broad thumbs and toes are characteristic of the Rubinstein-Taybi syndrome ${ }^{28}$ in which the coexisting cardiac malformation is usually patent ductus arteriosus.

19. The extra digit is almost always an accessory finger as in EVC syndrome, which is accompanied by a common atrium. Polydactyly of the hands is invariable in EVC syndrome, but polydactyly of the feet occurs in only $10 \%$ of patients.

20. Rocker-bottom appearance of the foot caused by the protruding heel in trisomy 18 , which is usually associated with patent ductus arteriosus or ventricular septal defect. ${ }^{12}$

\section{Chest and Abdomen}

1. Cutaneous venous collaterals over the anterior chest suggest chronic obstruction of the SVC or subclavian vein.

2. Asymmetric unilateral breast enlargement may occur due to aldosterone antagonists or digitalis glycosides ${ }^{29}$ treatment for heart failure.

3. Thoracic cage abnormalities: Pectus carinatum or pectus excavatum is seen in Marfan's syndrome and connective tissue disorders. Cor pulmonale is suspected in the barrel chest of emphysema or advanced kyphoscoliosis. The severe kyphosis may occur in ankylosing spondylitis. The "straight back syndrome" is associated with mitral valve prolapse.

4. Features of Turner's syndrome-shield chest is a broad chest with a greater angle than usual between the manubrium and body of the sternum, as well as widely separated nipples. In a female with neck webbing, wide carrying angle and short stature. (under $5 \mathrm{ft}$ in height). Short fourth metacarpal that becomes evident on making a fist is seen..$^{30}$ In Turner's syndrome, coarctation of aorta is seen. In a male, it is called Noonan's or Ullrich's syndrome and is commonly associated with pulmonary stenosis.

5. Postmyocardial infarction shoulder-hand syndrome is characterized by painless erythema of the palms and fingertips. The skin over the dorsa of the hands subsequently becomes swollen, tense, discolored, and wrinkled. The changes may culminate in Dupuytren's contractures. Pain, stiffness, and limitation of motion in the shoulder girdle, usually the left, may coexist. ${ }^{31}$

6. A thrill may be present over well-developed intercostal artery collaterals in patients with aortic coarctation.

7. Significant shunt lesions in infancy or childhood may cause chest wall deformities. The usual variety of chest deformity in such patients is anterior asymmetry, especially a left precordial bulge. When cardiac dyspnea in infants and young children causes chronic repetitive traction on the diaphragmatic insertions of the rib cage during growth and development, nonrachitic Harrison's grooves commonly result.

8. Scars on the chest may occur due to previous surgeries or healed chronic inflammations.

9. Abdominal paradox precedes the fall of oxygen saturation and a good indicator of respiratory failure. ${ }^{32}$

10. If clavicular movement upward is $>5 \mathrm{~mm}$, it suggests severe respiratory obstructive disease and correlating with forced expiratory volume (FEV), of $0.6 \mathrm{~L}^{33}$

11. The laryngeal height that is the distance from the top of the thyroid cartilage to the suprasternal notch; if it is $<4 \mathrm{~cm}$, postoperative pulmonary risk is high. ${ }^{34}$

12. The forced expiratory time (FET) is the best bedside predictor of the severity of airflow obstruction. FET $>6 \mathrm{sec}-$ onds corresponds to a forced expiratory volume in $1 \mathrm{sec}-$ ond/forced vital capacity $\left(\mathrm{FEV}_{1} / \mathrm{FVC}\right)<40 \%$. Conversely, FET $<5$ seconds indicates an $\mathrm{FEV}_{1} / \mathrm{FVC}>60 \%{ }^{35}$

13. The liver often is enlarged and tender in heart failure; systolic hepatic pulsations signify severe TR.

14. Patients with infective endocarditis of long duration may have splenomegaly.

15. Ascites can develop with advanced and chronic right heart failure or constrictive pericarditis.

16. The abdominal aorta usually may be palpated between the epigastrium and umbilicus in thin patients and children. Lateral expansion of an abdominal mass $>3 \mathrm{~cm}$ with pulsation suggests an abdominal aortic aneurysm. If expansile pulsations are present in a small aneurysm, it is more specific and less false negative but less frequently seen. This sign is so important that in a thin individual if expansile pulsations are absent, then better not to consider the aortic aneurysm diagnosis. ${ }^{36}$

17. Arterial bruits in the abdomen should be sought.

The eye is the chief means whereby the understanding may most fully and abundantly appreciate the infinite works of nature.

Leonardo da Vinci

\section{References}

1 Gombrich EH. Meditations on a Hobby Horse. London, UK: Phaidon;1978

2 Murphy Joseph G, Lloyd Margaret A. Cardiovascular examination. In: Mayo Clinic Cardiology: Concise Textbook. 4th ed. Section I Fundamentals of Cardiovascular Disease, 
Clarence Shub. Mayo Clinic Scientific Press Oxford University Press:1-26, chap 1

3 Dabestani A, Child JS, Henze E, et al. Primary hemochromatosis: anatomic and physiologic characteristics of the cardiac ventricles and their response to phlebotomy. Am J Cardiol 1984;54(1):153-159

4 Fang JC, O'Gara PT. The history and physical examination: an evidence based-approach. In: Libby PP, Bonow RO, Mann DL, and Zipes DP, eds. Braunwald's Heart Disease: A Textbook of Cardiovascular Medicine. 8th ed. Philadelphia, PA: Elsevier Science; 2007

5 Salvatore M. In: Chest inspection, palpation, and percussion. Physical Diagnosis Secrets. 2nd ed. Philadelphia, PA: Mosby Elsevier;2007:371, chap 13

6 Freedom RM, Gerald PS. Congenital cardiac disease and the "cat eye" syndrome. Am J Dis Child 1973;126(1):16-18

7 Perloff JK, Phelps ET. A review of Werner's syndrome, with a report of the second autopsied case. Ann Intern Med 1958;48(6):1205-1220

8 Salvatore M. In: General appearance, facies, and body habitus. Physical Diagnosis Secrets. 2nd ed. Philadelphia, PA: Mosby Elsevier; 7 September 2007:18, chap 1

9 Salvatore M. In: General appearance, facies, and body habitus. Physical Diagnosis Secrets. 2nd ed. Philadelphia, PA: Mosby Elsevier; 7 September 2007:20, chap 1

10 Miranda WR, Nishimura RA. The history, physical examination, and cardiac auscultation. In: Fuster V, Harrington RA, Jagat N, Eapen ZJ, eds. Hurst's The Heart. 14th ed. New York, NY: McGraw-Hill Education; 2017:228

11 Farquhar JW. The child of the diabetic woman. Arch Dis Child 1959;34(173):76-96

12 Perloff JK. The Clinical Recognition of Congenital Heart Disease. 5th ed. Philadelphia, PA: WB Saunders;2003

13 Rentería VG, Ferrans VJ, Roberts WC. The heart in the Hurler syndrome: gross, histologic and ultrastructural observations in five necropsy cases. Am J Cardiol 1976;38(4):487-501

14 Clarren SK, Smith DW. The fetal alcohol syndrome. N Engl J Med 1978;298(19):1063-1067

15 Cayler GG, Blumenfeld CM, Anderson RL. Further studies of patients with the cardiofacial syndrome. Chest 1971;60(2):161-165

16 Talley NJ, Simon O. Section 1: The general principles of history taking and physical examination. Examination Medicine-E-Book. 8th ed. A Guide to Physician Training. 15 October 2016:30

17 Roberts NK, Perloff JK, Kark RAP. Cardiac conduction in the Kearns-Sayre syndrome (a neuromuscular disorder associated with progressive external ophthalmoplegia and pigmentary retinopathy). Am J Cardiol 1979;44:1396

18 Hollenhorst RW. Significance of bright plaques in the retinal arterioles. JAMA 1961;178:23-29

19 Silverman KJ, Hutchins GM, Bulkley BH. Cardiac sarcoid: a clinicopathologic study of 84 unselected patients with systemic sarcoidosis. Circulation 1978;58(6):1204-1211

20 Jeresaty RM, Huszar RJ, Basu S. Pierre Robin syndrome. Cause of respiratory obstruction, cor pulmonale, and pulmonary edema. Am J Dis Child 1969;117(6):710-716
21 Allen HD, Philips JR, Chan DP. History and physical examination. Vol. 1 Part II-Diagnostic methods. In: Allen HD, Driscoll DJ, Shaddy RE, Feltes TE, eds. Moss and Adams' Heart Disease in Infants, Children, and Adolescents: Including the Fetus and Young Adults. 7th ed. Philadelphia, PA: Lippincott Williams and Wilkins; 2007

22 Ruppert GB, Lindsay J, Barth WF. Cardiac conduction abnormalities in Reiter's syndrome. Am J Med 1982;73(3):335-340

23 Mills NL, Japp AG, Robson J. The cardiovascular system. In: Alastair Innes J, Dover AR, Fairhurst K, eds. Macleod's Clinical Examination. 14th ed. Amsterdam, The Netherlands: Elsevier; 2018:46, chap 4

24 Salvatore M. Physical Diagnosis Secrets. 2nd ed. Philadelphia, PA: Mosby Elsevier; 7 September 2007:1

25 Salvatore M. In: Appearance, facies, and body habitus. Physical Diagnosis Secrets. 2nd ed. Philadelphia, PA: Mosby Elsevier; 7 September 2007:13, chap 1

26 Muhammad I, Ahmed NS, eds. In: History taking and physical examination. Bedside Techniques Methods of Clinical Examination. 4th ed. Karachi, Pakistan: Paramount Publishing Enterprise;2013:15

27 Bittl JA, Perloff JK. Chronic post-rheumatic fever arthropathy of Jaccoud. Am Heart J 1983;105(3):515-517

28 Gellis SS, Feingold M. Rubinstein-Taybi syndrome. Am J Dis Child 1971;121(4):327-328

29 Lewinn EB. Gynecomastia during digitalis therapy; report of eight additional cases with liver-function studies. N Engl J Med 1953;248(8):316-320

30 Muhammad I, Ahmed NS, eds. In: History taking and physical examination. Bedside Techniques Methods of Clinical Examination. 4th ed. Karachi, Pakistan: Paramount Publishing Enterprise;2013:18

31 Edeiken J. Shoulder-hand syndrome following myocardial infarction with special reference to prognosis. Circulation 1957;16(1):14-19

32 Salvatore M. In: Chest inspection, palpation, and percussion. Physical Diagnosis Secrets. 2nd ed. Philadelphia, PA: Mosby Elsevier; 7 September 2007:378, chap 13

33 Salvatore M. In: Chest inspection, palpation, and percussion. Physical Diagnosis Secrets. 2nd ed. Philadelphia, PA: Mosby Elsevier; 7 September 2007:392, chap 13

34 Salvatore M. In: Chest inspection, palpation, and percussion. Physical Diagnosis Secrets. 2nd ed. Philadelphia, PA: Mosby Elsevier; 7 September 2007:395, chap 13

35 Straus SE, McAlister FA, Sackett DL, Deeks JJ; CARE-COAD2 Group. Clinical Assessment of the Reliability of the Examination-Chronic Obstructive Airways Disease. Accuracy of history, wheezing, and forced expiratory time in the diagnosis of chronic obstructive pulmonary disease. J Gen Intern Med 2002;17(9):684-688

36 Salvatore M. Physical Diagnosis Secrets. 2nd ed. Philadelphia, PA: Mosby Elsevier; 7 September 2007:7 